\title{
The practice of essential nutrition actions in healthcare deliveries of Shebedino District, South Ethiopia
}

\author{
Habte Bolka ${ }^{1}$, Amanuel Alemu Abajobir ${ }^{2 \star}$ \\ ${ }^{1}$ School of Public Health, Health Sciences College, Hawassa University, Hawassa, Ethiopia \\ ${ }^{2}$ Public Health Department, Health Sciences College, Debremarkos University, Debremarkos, Ethiopia; \\ *Corresponding Author: abjobir64@yahoo.com
}

Received 18 July 2013; revised 19 August 2013; accepted 2 September 2013

Copyright (C) 2014 Habte Bolka, Amanuel Alemu Abajobir. This is an open access article distributed under the Creative Commons Attribution License, which permits unrestricted use, distribution, and reproduction in any medium, provided the original work is properly cited. In accordance of the Creative Commons Attribution License all Copyrights (C) 2014 are reserved for SCIRP and the owner of the intellectual property Habte Bolka, Amanuel Alemu Abajobir. All Copyright (C) 2014 are guarded by law and by SCIRP as a guardian.

\section{ABSTRACT}

The essential nutrition actions explain nutrition through life cycle approach addressing women's nutrition during pregnancy and lactation, optimal infant and young children feeding, nutritional care for sick children and control of anemia, iodine and vitamin A deficiencies. Essential nutrition action has been implemented and resulted in positive outcome in less developed countries. However, the status of practice and associated factors were not studied in Ethiopia. Thus, institution-based cross-sectional study was conducted to assess the practice of essential nutrition actions in healthcare deliveries of Shebedino District, South Ethiopia. Quantitative data were collected though face-to-face interview with health workers and triangulated with data obtained through in-depth interview with health managers in the district and non-participatory observation of client-provider interaction in health facilities. Data were analyzed using SPSS16.0 software. Descriptive and logistic regression analyses were undertaken. The study revealed that $61(56.0 \%)$ health workers practiced essential nutrition actions. Seventy one (65.1\%) health workers were trained on essential nutrition actions. The practice of essential nutrition actions was associated with career structure of the health workers $(A O R=6.79,95 \% \mathrm{Cl}$ : 2.31, 19.98), essential nutrition actions knowledge of health workers (AOR $=6.87,95 \% \mathrm{Cl}$ : 2.11 , 21.51) and availability of monthly nutrition related report form $(A O R=4.95,95 \% \mathrm{Cl}$ : 1.46 ,
16.81). The practice of essential nutrition actions was low. The factors affecting the practice were inadequate training and knowledge of essential nutrition actions, career structure of the health workers and availability of monthly report form. Training should be provided for health workers on essential nutrition actions; moreover, essential nutrition actions indicators should be included in monthly report forms of the health institutions.

\section{KEYWORDS}

Essential Nutrition Actions; Practice; Healthcare Deliveries; Ethiopia

\section{INTRODUCTION}

Malnutrition is one of the most serious public health problems in developing countries, where inadequate access to food and nutrients, poor care for mothers and children, derisory health services and unhealthy environments are common [1].

Implementation of ENA package promotes and supports the achievement of seven priority nutrition behaviors. These behaviors are exclusive breastfeeding for six months, adequate complementary feeding starting at about six months with continued breastfeeding for two years, appropriate nutritional care of sick and severely malnourished children, adequate intake of vitamin A for women and children, adequate intake of iron for women and children, adequate intake of iodine by all members of the household and maternal nutrition. These interventions should be included in integrated package at all 
health services contact points; namely, antenatal care, delivery, postnatal and family planning, vaccination, sick child and well child visits [1].

In poor countries maternal and child under nutrition is the underlying cause of more than one-third of all child deaths under the age of five [2]. Pregnancy to age of 24 months of child is the critical window of opportunity for delivery of nutrition interventions. If children are not provided with proper nutrition before the age of 24 months, they may suffer from irreversible damage into their adult life and to the subsequent generations [3]. Strategies to improve the nutritional status and growth of children should include interventions to improve nutrition of pregnant and lactating women; early initiation of breastfeeding with exclusive breastfeeding for 6 months; promotion, protection and support of continued breastfeeding along with appropriate complementary feeding from 6 months to 2 years and beyond; and micronutrient supplementation, targeted fortification and food supplementation when needed [4].

The essential nutrition actions (ENA) framework has been developed with the support of United States Agency for International Development (USAID) and implemented in Africa and Asia since 1997 [5]. It is an operational framework for managing the advocacy, planning and the delivery of an integrated package of preventive nutritional actions encompassing infant and young child feeding (IYCF), micronutrients and the nutrition of woman. It uses multiple contact points and targets health services and behavior change communication (BCC) support to women and young children during the first 1000 days of life.

This period is critical as nutrient requirements are increased, the risks of under nutrition are great and the consequences of deficiencies are most likely to be ireversible [5]. It is believed that breastfeeding counseling, appropriate complementary feeding and vitamin A and zinc are important to reduce child deaths and future diseases burden related to under nutrition.

The ENA framework explains nutrition through life cycle approach addressing women's nutrition during pregnancy and lactation, optimal infant and young child feeding, nutritional care for sick children and control of anemia, iodine and vitamin A deficiencies. It also underlines using multiple contact points at health institutions and beyond to reach mothers and children to provide and reinforce ENA messages. The goal is to capitalize on multiple program opportunities and communication channels to deliver life cycle appropriate nutrition messages at every opportunity possible to pregnant women and mother with children under age of two years and other care givers and influential family members [5].

The implementation of ENA resulted in positive outcomes even in less developed countries [6]. The actions that make up "essential package" for nutrition are relatively inexpensive and proven to be effective in different settings. They need to be incorporated into both child and maternal health services at the community level and in clinics. Primary healthcare should accompany nutrition interventions at each level [6]. It prioritizes actions on nutrition such as reducing missed opportunities by incorporating key nutrition services and messages into existing health services contact points. This combined with the strategic selection of a network of community organizations to reach high coverage is one of the guiding principles of the approach [7]. According to the review of the integration of ENA in public health service delivery points of Ethiopia, advocacy, training and support from stakeholders were conditions that facilitated institutionalization of its practice while lack of formal approval for the draft of National Nutrition Strategy, lack of ENA-related indicators in the Health Management Information System (HMIS) and lack of regularly scheduled training courses on ENA for new and continuing healthcare professionals were inhibitory factors [8]. Supervisor visit, attitudes of health managers, availability of micronutrient supplies and availability of information, education, and communication (IEC) materials were factors associated with practice of ENA [9]. In March and June 2003, LINKAGES organized technical updates to introduce ENA approaches to the government, donors, and implementing organizations. Accordingly, the Ethiopian Federal Ministry of Health (FMoH) adopted this approach and included it in child survival strategies in 2004. However, the status of practice and associated factors were not studied in Ethiopia. Thus, this study aimed to assess the practice of essential nutrition actions and factors associated with it in healthcare deliveries of Shebedino district, South Ethiopia to inform policy makers and nutrition program on factors that facilitate and inhibit the practice of ENA, guide to formulate strategies to improve nutrition services to the target groups, the community and to be used as a baseline evidence for other researchers in the area.

\section{METHODS}

\subsection{Study Design, Area and Period}

A facility-based cross-sectional study employing both quantitative and qualitative methods was conducted in Shebedino district, South Ethiopia, from 14th January to 26th February 2012.

\subsection{Study Population}

The source populations were all health professionals who were working at heath posts, maternal and child health $(\mathrm{MCH})$ departments of health centers and health 
service managers of the district.

\subsection{Sample Population}

The key informants including heads of health centers, professionals working in $\mathrm{MCH}$ departments and the district health office managers were the sample populations; client-provider interaction in health posts and MCH departments of health centers was observed.

\subsection{Sample Size and Sampling Technique}

All healthcare workers in selected health posts and MCH department of health centers were included in the study: 43 nurses from health centers and 75 health extension workers (HEW) from health posts.

Purposive sampling method was employed for both indepth interview and observation of client-provider interaction in selected health facilities; accordingly, 9 indepth interviews and 20 observations for client-provider interaction in 10 health posts and 2 health centers were selected.

\subsection{Data Collection Procedure}

Semi-structured interviewer administered questionnaire, interview guide and checklist adapted from "program review of ENA: checklist for district health service" were used to collect quantitative data [10].

In-depth interview with key informants and observation at health posts and MCH departments of health centers were used to collect qualitative data by note taking and tape recording. Data from observations were collected by using non-participatory checklists.

\subsection{Data Analysis}

Data were entered in Epi Data 3.1 and exported to SPSS 16.0 for cleaning, transformation and analysis. Frequency distribution, percentage and mean were calculated. Odds ratios with $95 \%$ confidence interval (CI) were calculated to predict associations between dependent and independent variables. Variables with $\mathrm{p}<0.25$ on bivariate analysis were entered into model to remove confounding. Statistical significance was set at $\mathrm{p} \leq 0.05$. Framework analysis was used to summarize transcribed and coded qualitative data.

\subsection{Data Quality Control}

Before actual data collection training was given on ethics of research, observation, recording and interview techniques for data collectors and supervisor. Questionnaire was pre-tested; data collection was supervised by a health officer and the principal investigators. Double data entry was applied to preserve consistency of data.

\subsection{Study Variables}

\subsubsection{Dependent Variable}

- Practice of ENA in healthcare delivery points.

\subsubsection{Independent Variables}

- Back ground characteristics of health workers.

- ENA knowledge of health workers.

- Attitude of health towards ENA.

- ENA training given to health workers.

- Availability of supervision.

- Availabilities of micronutrient supplementation.

- Availability of monthly report form that includes nutrition indicators.

- Perception of healthcare managers towards ENA.

- Availability of support from stakeholders.

\subsection{Definitions}

ENA: is an operational framework for managing the advocacy, planning and the delivery of an integrated package of preventive nutritional actions encompassing infant and young child feeding (IYCF), micro nutrients and the nutrition of woman.

Behaviors of ENA: are nutrition actions that include optimal breastfeeding, optimal complementary feeding, sick child feeding, woman nutrition, prevention of iron deficiency anemia, prevention of vitamin A deficiency and prevention of iodine deficiency disorder.

ENA fully practiced: when all recommended behaviors of ENA delivered to pregnant woman and mothers/care taker with under-two year children.

ENA not fully practiced: when some recommended behaviors of ENA not delivered to pregnant woman and mother/care taker with under-two year children.

Knowledge: seven ENA behaviors, six ENA contacts, three integration sites, three components and two target groups were asked.

Promoted knowledge: those health workers who score above median for knowledge questions.

Not promoted knowledge: those health workers who score below median for knowledge questions.

\subsection{Ethical Consideration}

Ethical clearance was obtained from Haramaya University; School of Public Health institutional research ethics review committee. Official letter of cooperation was written to Shebedino district health office. Written informed consent was obtained from each participant; confidentiality was maintained.

\section{RESULTS}

\subsection{Background Characteristics of Healthcare Workers}

A total of 109 health workers interviewed and in- 
cluded in the analysis. Non-response rate was $7.6 \%$. Ninety $(83 \%)$ of the respondents were females. The age ranged between 20 - 35 years with mean age of 26 year $(\mathrm{SD} \pm 2.78)$. Majority of them 66 (60.6\%) were HEW. Sixty three (58\%) respondents worked for more than four years (Table 1 ).

\subsection{ENA Practice of Health Workers}

Among the health workers (HW), 71 (65.1\%) were trained on ENA. The training was in-service and delivered by non-governmental organizations (NGO). From 66 HEW, 56 (78.9\%) were trained on ENA; while out of 43 nurses, 15 (21.1\%) were given training on ENA. However, only 6 (5.5\%) health workers received refreshment training of ENA. Fifty five (77.5\%) health workers trained on ENA, practice ENA fully. Among respondents who received ENA training, 71 (65.1\%), claimed of implementing ENA in their department.

The majority, 103 (94.5\%) and 98 (89.9\%), of health workers reported delivering of iron/folic acid and counseling of diet in pregnancy respectively during antenatal care (ANC) visits. Similarly, 105 (96.3\%) and 95 (87.2\%) HW reported counseling of optimal breast feeding during delivery and vaccination visits respectively. One hundred one (93\%) HW reported practice of growth monitoring and vitamin A supplementation during sick child and vaccination visits respectively. Ninety four (86.2\%) and 86 (78.9\%) HW reported counseling on diet during lactation in postnatal family planning and delivery visits respectively (Table 2).

\subsection{Attitude of Health Workers}

Attitude of all HW who received ENA training (65.1\%) was positive towards ENA.

Table 1. Background characteristics of healthcare workers in Shebedino District, South Ethiopia, 2012.

\begin{tabular}{cccc}
\multicolumn{2}{c}{ Characteristics } & Frequency & Percent \\
\hline Sex & Male & 19 & 17.4 \\
& Female & 90 & 82.6 \\
Profession & Nurse & 43 & 39.4 \\
& HEW & 66 & 60.6 \\
& $<2$ & 7 & 6.4 \\
Service year & $2-4$ & 39 & 35.8 \\
& $4-6$ & 55 & 50.5 \\
& $>6$ & 8 & 7.3 \\
& Yes & 71 & 65.1 \\
\hline
\end{tabular}

Table 2. Health workers practice of ENA during ANC, Delivery, Immunization, sick child and postnatal and family planning visits in Shebedino District, South Ethiopia in 2012.

\begin{tabular}{|c|c|c|c|}
\hline Variables & Services provided & Frequency & Percent \\
\hline \multirow{5}{*}{$\begin{array}{l}\text { ENA at } \\
\text { ANC visit }\end{array}$} & Iron/folic acid & 103 & 94.5 \\
\hline & Diet during pregnancy & 98 & 89.9 \\
\hline & Optimal breastfeeding & 77 & 70.6 \\
\hline & Iodized salt & 63 & 57.8 \\
\hline & Deworming & 51 & 46.8 \\
\hline \multirow{5}{*}{$\begin{array}{c}\text { ENA at } \\
\text { delivery visit }\end{array}$} & Optimal breast feeding & 105 & 96.3 \\
\hline & Vitamin A & 95 & 87.2 \\
\hline & Diet during lactation & 86 & 78.9 \\
\hline & Iron/folic acid & 63 & 57.8 \\
\hline & Iodized salt & 58 & 53.2 \\
\hline \multirow{6}{*}{$\begin{array}{c}\text { ENA at } \\
\text { immunization } \\
\text { visit }\end{array}$} & Vitamin A & 101 & 92.7 \\
\hline & Optimal breast feeding & 95 & 87.2 \\
\hline & $\begin{array}{l}\text { Optimal complementary } \\
\text { feeding }\end{array}$ & 81 & 74.3 \\
\hline & Growth monitoring & 70 & 64.2 \\
\hline & Iron/folic acid & 54 & 49.5 \\
\hline & Iodized salt & 48 & 44.0 \\
\hline \multirow{5}{*}{$\begin{array}{l}\text { ENA at sick } \\
\text { child visit }\end{array}$} & Growth monitoring & 101 & 92.7 \\
\hline & Sick child feeding & 90 & 82.6 \\
\hline & Vitamin A & 76 & 69.7 \\
\hline & Iron/folic acid & 70 & 64.2 \\
\hline & Iodized salt & 44 & 40.4 \\
\hline \multirow{5}{*}{$\begin{array}{c}\text { ENA at } \\
\text { postnatal and } \\
\text { family planning } \\
\text { visit }\end{array}$} & Optimal breastfeeding & 88 & 80.7 \\
\hline & $\begin{array}{l}\text { Optimal complementary } \\
\text { feeding }\end{array}$ & 72 & 66.1 \\
\hline & Lactational amenorrhea & 68 & 62.4 \\
\hline & $\begin{array}{c}\text { Effect of family } \\
\text { planning on breast milk }\end{array}$ & 55 & 50.5 \\
\hline & Iodized salt & 44 & 40.4 \\
\hline
\end{tabular}

"Multiple responses were possible.

They believed that implementation of ENA can improve nutritional status of both mothers and children.

\subsection{ENA Knowledge of Health Workers}

Above fifty percent of HW knew ENA behaviors. Seventy one (65.0\%) respondents knew optimal breast feeding followed by 70 (64.2\%) optimal complementary feeding. The prevention of iodine deficiency (53.2\%) was less known behavior. About $60 \%$ of HW knew ENA 
contact points; seventy (64.2\%) respondent knew immunization followed by 68 (62.4\%) pregnancy. Less known contact point of ENA was well child and growth monitoring (45.9\%). Seventy one (65.1\%) HW knew ENA could be integrated into health sectors followed by 53 (48.6\%) integration into community. Relatively small number 25 (22.9\%) of HW added other sectors like education, agriculture, etc. About $60 \%$ of HW were aware of targets of ENA; seventy (64.2\%) HW cited pregnant and lactating mothers, while 69 (63.3\%) indicated under two year children. Around half of the respondent were aware of components of ENA; sixty five (59.9\%) HW knew IYCF followed by woman nutrition 62 (56.9\%) (Table 3).

\subsection{Factors Associated with Practice of ENA}

From interviewed 109 HW, only 61 (56.0\%) practiced ENA fully. Respondents reported that lack of refreshment training 38 (34.9\%), less support from health office 28 (25.7\%), less support from NGOs 25 (22.9\%) and lack of training 38 (34.9\%) were problems to implement ENA fully.

The majority of HW104 (95.4\%) had regular supervisory visits. However, only 35 (32.1\%) had supervision that included nutrition actions. From those HW who received supervisory visits on nutrition action, $74.3 \%$ practiced ENA fully. Twenty three (21\%) respondents reported shortage of vitamin A supplement in the last 30 days. Shortage of iron supplement and IEC materials in the last 30 days was reported by 17 (15.6\%) and 37 (33.9) respondents respectively.

Thirty three (30.3\%) respondents reported the availability of monthly report form that included nutrition indicators. Twenty seven (81.8\%) HW, who reported availability of monthly report form practiced ENA fully.

On bivariate analysis, professional structure of health workers, supervision, monthly report form, IEC material stock out in the last 30 days, promoted knowledge of ENA of HW and vitamin A stock out had p-values less than 0.25. However, HW profession $(\mathrm{COR}=6.15,95 \% \mathrm{CI}$ : $2.64,14.35)$, supervision on nutrition actions (COR = 3.22, 95\%CI: $1.33,7.79)$, monthly report that included nutrition indicators $(\mathrm{COR}=5.56,95 \% \mathrm{CI}=2.06,15.01)$ and promoted knowledge of ENA (COR $=7.68$, 95\%CI: $3.14,18.77$ ) were significantly associated with the full practice of ENA (Table 4).

The full practice of ENA was strongly associated with knowledge on ENA. Health workers with promoted knowledge of ENA were 7 times more likely to practice ENA fully than those HW with no promoted knowledge of ENA (AOR = 6.87, 95\%CI: 2.11, 21.51).

The career category of HW was strongly associated with full practice of ENA; HEW were 7 times more
Table 3. Health workers knowledge about behaviors, contact points, integration sites, target groups and components of ENA in Shebedino District, South Ethiopia in 2012.

\begin{tabular}{|c|c|c|}
\hline Variables & Frequency & Percent \\
\hline \multicolumn{3}{|l|}{$\begin{array}{l}\text { Knowledge about ENA } \\
\text { behaviors }(\mathrm{N}=109)\end{array}$} \\
\hline Optimal breastfeeding & 71 & 65.1 \\
\hline Optimal complementary feeding & 70 & 64.2 \\
\hline Sick child feeding & 67 & 61.5 \\
\hline Women nutrition & 68 & 62.4 \\
\hline Prevention iron deficiency anemia & 66 & 60.6 \\
\hline Prevention of vitamin A deficiency & 66 & 60.6 \\
\hline Prevention of iodine deficiency disorder & 58 & 53.2 \\
\hline \multicolumn{3}{|l|}{$\begin{array}{l}\text { Knowledge about ENA } \\
\text { contact points }(\mathrm{N}=109)\end{array}$} \\
\hline Pregnancy & 68 & 62.4 \\
\hline Delivery & 67 & 61.5 \\
\hline Postnatal and family planning & 67 & 61.5 \\
\hline Immunization & 70 & 64.2 \\
\hline Sick child & 61 & 56.0 \\
\hline Well child and growth monitoring & 50 & 45.9 \\
\hline \multicolumn{3}{|l|}{$\begin{array}{l}\text { Knowledge about ENA } \\
\text { integration sites }(\mathrm{N}=109)\end{array}$} \\
\hline Health sector & 71 & 65.1 \\
\hline Community & 53 & 48.6 \\
\hline Other sectors & 25 & 22.9 \\
\hline \multicolumn{3}{|l|}{$\begin{array}{l}\text { Knowledge about ENA } \\
\text { target groups }(\mathrm{N}=109)\end{array}$} \\
\hline Pregnant and lactating mothers & 70 & 64.2 \\
\hline Children under age of two years & 69 & 63.3 \\
\hline \multicolumn{3}{|l|}{$\begin{array}{l}\text { Knowledge about ENA } \\
\text { components }(\mathrm{N}=109)\end{array}$} \\
\hline Infant and young child feeding & 65 & 59.6 \\
\hline Micronutrient & 59 & 54.1 \\
\hline Woman nutrition & 62 & 56.9 \\
\hline
\end{tabular}

${ }^{*}$ Multiple responses were possible.

likely to practice ENA fully than nurses (AOR $=6.79$, 95\%CI: 2.31, 19.98).

Availability of monthly report form that included nutrition actions was also associated with full practice of ENA; those HW who reported availability of monthly report form that included nutrition actions were 5 times more likely to practice ENA fully than those denied monthly report form $(\mathrm{AOR}=4.95,95 \% \mathrm{CI}: 1.46,16.81)$ (Table 4). 
Table 4. Bivariate and multivariable analysis of factors associated with practice of ENA in Shebedino District, South Ethiopia in 2012.

\begin{tabular}{|c|c|c|c|c|}
\hline \multirow{2}{*}{ Variables } & \multicolumn{2}{|c|}{ Practice of ENA } & \multirow{2}{*}{ COR $(95 \% \mathrm{CI})$} & \multirow{2}{*}{ AOR (95\%CI) } \\
\hline & Fully & Not fully & & \\
\hline \multicolumn{5}{|l|}{ Profession } \\
\hline HEW & 48 & 18 & $6.15(2.64,14.35)^{* *}$ & $6.79(2.31,19.98)^{* *}$ \\
\hline Nurse & 13 & 30 & 1.00 & 1.00 \\
\hline \multicolumn{5}{|c|}{ Supervision for ENA } \\
\hline Yes & 26 & 9 & $3.22(1.33,7.79)$ & $2.66(0.87,8.12)$ \\
\hline No & 35 & 39 & 1.00 & 1.00 \\
\hline \multicolumn{5}{|c|}{ Monthly report form include nutrition activities } \\
\hline Yes & 27 & 6 & $5.56(2.06,15.01)^{* * *}$ & $4.95(1.46,16.81)$ \\
\hline No & 34 & 42 & 1.00 & 1.00 \\
\hline \multicolumn{5}{|c|}{ IEC material stock out with in last 30 days } \\
\hline Yes & 17 & 20 & $0.54(0.18,1.28)$ & $0.49(0.15,1.59)$ \\
\hline No & 44 & 28 & 1.00 & 1.00 \\
\hline \multicolumn{5}{|l|}{ Knowledge ENA } \\
\hline promoted & 39 & 9 & $7.68(3.14,18.77)^{* *}$ & $6.87(2.11,21.51)^{* *}$ \\
\hline Not promoted & 22 & 39 & 1.00 & 1.00 \\
\hline \multicolumn{5}{|c|}{ Vitamin A stock out with in last 30 days } \\
\hline Yes & 7 & 16 & $0.48(0.18,1.28)$ & $0.87(0.25,3.16)$ \\
\hline No & 41 & 45 & 1.00 & 1.00 \\
\hline
\end{tabular}

${ }^{* *}$ p-value $<0.001$.

\subsection{Results from Qualitative Data}

The ENA implementation was started in 2004 with training support delivered by Essential Service for Health in Ethiopia (ESHE). Since then with increasing number of ENA trained staffs, its practice increased from year to year.

As MCH department head of the district health office indicated, "ENA has been widely implemented in the district with much emphasis given to implementation in the community."

During the in-depth interview, it was found that, attitude of health managers towards ENA was positive. They underlined that the implementation of ENA will bring an optimistic impact on the health of children and mothers.

One of the heads of health centers said that, "I strongly believe that implementation of ENA can bring a great benefit for mothers and children."

MCH department head of district health office pointed that, "An ENA package consists of interventions that should reach each household; implementation of these interventions will result in better health for children and mothers. That is why we are trying to reach all targets in the community through HEW."

All key informants agreed on the need for more ENA trainings. The problem was on the number of training given for each health institution and high attrition of ENA trained health workers. The reason for high attrition of ENA trained HW was transferred to other districts or private sectors; low rate of refreshment training was also cited.

The MCH department head of one health center said that, "Four years ago four persons, including me, received ENA training from this institution. The training was good and we started practicing it; however, two of the trained colleagues left the institution."

$\mathrm{MCH}$ department head of the district health office indicated that, "At this time, 8 health workers are on essential nutrition actions-behavior change communication (ENA-BCC) training. We had been giving training at least twice a year. Though we trained more than 30\% nurses, majority of them left their position due to transfer 
to private sectors and to other districts. Some of our staffs trained on ENA five or six years ago need refreshment training; this is the other problem."

One of the heads of health centers indicated, "In this institution we are delivering all MCH services, but we have only two staffs who received ENA training."

Generally supportive supervision from district health office looked strong. Health workers were supervised by one supervisor nominated for five health posts by health center once a week. However, supportive supervision may or may not include essential nutrition actions.

The MCH department head of health center said that, "at least once a month, supervisors come to our institution but they never asked us about the practice of ENA."

The MCH department head of the district health office also pointed that "we cannot say comfortably that our entire supervisors include ENA in their supervision, since we have supervisors who are not trained on ENA."

Support from NGO was found to be encouraging; the $\mathrm{MCH}$ department head of the district health office reported that multiple NGO were working in providing the training, IEC materials, and financial support.

\subsection{Results from Observations of Client-Provider Interaction}

In observed institutions, almost all pregnant woman received counseling on diet during pregnancy. About half of them received iron/folic acid supplementation; however, in observed health posts none of the pregnant women received counseling on using iodized salt.

Almost all postpartum women received counseling on initiation of breastfeeding. Majority of them were counseled on diet and vitamin A supplementation. Very few pregnant and postpartum women received counseling on using iodized salt.

Weight and palmar pallor of all children who visited health institutions for vaccination services were assessed. During sick child visit, weight, palmar pallor and edema were assessed for all children. Some mothers/care takers, during sick child visit, were asked about feeding practice and counseled on feeding the sick child. However, the majority of mothers/care takers who visited health institutions for child vaccination were assessed for feeding practice and counseled to continue breastfeeding up to two years.

The majority of children during treatment for their sickness were checked for vitamin A supplementation protocol and supplemented accordingly. The vitamin A supplementation status for all children was checked/recorded on their card during their visit for vaccination.

\section{DISCUSSION}

All ENA behaviors should be practiced together, not separately. The full practice of ENA was low (56\%). This might be due to the small proportion of HW who received training on ENA, which was $65.1 \%$.

Absence of ENA indicators in health monitoring information system was identified to inhibit incorporation of ENA in daily service delivery [8]. This study identified positive association between availability of report form that included nutrition indicators and full practice of ENA as the availability of such indicators ease the monitoring and evaluation mechanism.

Professional structure of $\mathrm{HW}$ was associated with full practice of ENA; HEW were more likely to practice ENA than nurses; this might be due to small proportion of ENA trained nurses than HEW (21.1\% vs. 78.9\%).

Promoted knowledge of ENA had positive association with full practice of ENA; this might be due to the change of attitude of HW towards ENA. Proportion of promoted knowledge is higher in HEW than nurses. This was different from review of incorporation of ENA in public health programs in Ethiopia, where HW in ANC unit were more knowledgeable [8]; this might be due to training difference; more HEW were trained on ENA than those in ANC.

The majority 104 (95.4\%) of HW had regular supervisory visits; however, only 35 (32.1\%) had supervisions that included nutrition actions. About three quarters of HW practiced ENA fully. This is in line with the result from Malawi where nearly all Health Surveillance Assistants (HAS) received supervisory visit [8]. This might be due to positive attitude of administrative staffs towards ENA.

It was found that, attitude of administrative staffs of health office towards ENA was positive. Similarly, all HW who received ENA training had positive attitude towards ENA. This finding goes with the findings of other studies in which administrative staffs described ENA as clear, useful and critical importance within health system [8]; the study from Malawi shows similar result. The district health management team members perceived the Community ENA Program as a big benefit to women of child bearing age and children less than five years of age. They had also observed spill over benefits to other family members [9].

Shortage of vitamin A and iron supplementation in the last 30 days was reported by 23 (21\%) and 17 (15.6\%) of HW. In this period none of pregnant women and children received vitamin A and iron supplement. This result is similar with review of antenatal register at Bimbi health center in Malawi where none of pregnant women and children received vitamin A and iron/folic acid supplement. The reason was shortage of micronutrient supplies in the health center [9]. The ENA services were delivered in all departments where almost all respondents of exit interview received at least 2 - 4 recommended services. 
During ANC and delivery visit, $44.3 \%$ and $33.3 \%$ of woman respectively were supplied with iron/folic acid. In observed health institutions majority of them were supplied with iron/folicacid supplementations. This is lower than the finding from Madagascar where $76 \%$ of pregnant mothers were supplied with iron/folic acid [11]. The discrepancy might be due to ENA is long rooted in Madagascar. During initiation of ENA package in Ethiopia, lessons were learned from LINKAGES programs in other countries, particularly Madagascar guided program design and were adapted for Ethiopia [11].

Generally, during all contacts, delivering of counseling on breast feeding was found to be high (above 65\%). This is might be due to the universality of breastfeeding practice in Ethiopia and can in turn be used as entry point for other interventions.

During ANC visit supplementation of iron/folic acid was found to be low (44.3\%). This might be resulted from HW fatigue due to less compliance of pregnant women towards completing the recommended dozes.

The sources of training for all HW on ENA were NGOs. This finding goes with findings of incorporation of ENA in public health programs of Ethiopia which shows that, NGOs participate by providing capacity building training, producing advocacy materials and providing monetary support. This also agreed with the result from in-depth interview.

Staff turnover was a major problem; this finding is similar with the findings of review of incorporation of ENA in to public health programs of Ethiopia which depicts staff turnover as major inhibitor of integration of ENA [12].

\section{CONCLUSION}

This study provided a baseline finding for the status of ENA implementation in healthcare deliveries of the district. In this study almost all mothers and children got some services in ENA package. Optimal breastfeeding counseling was found to be high while counseling on use of iodized salt was low. Full practice of ENA was low (56\%) in healthcare deliveries of the district. Full practice of ENA was associated with professional structure and promoted knowledge on ENA of HW and availability of monthly report form that included nutrition indicators. General supervisory visits to health institutions were found to be encouraging (95.4\%); however, supervisory visits including nutrition actions were found to be low (32.1\%).

\section{RECOMMENDATIONS}

To increase the full practice of ENA in healthcare deliveries, ENA training to HW is inevitable. Therefore, regional health bureaus should provide more ENA training for nurses and refreshment training for
HEW. The HMIS report form should include ENA indicators. Moreover, regular supportive supervisory visits should also be made.

\section{REFERENCES}

[1] Diene, S. (2003) The essential nutrition action, BASIC support for institutionalizing child survival (BASICII) project.

http://www.basics.org/documents/pdf/ENA.pdf

[2] Bhutta, Z.A., Ahmed, T., Black, R.E., Cousens, S., Dewey, K., Giugliani, E., Haider, B.A., Kirkwood, B., Morris, S.S., Sachdev, H.P.S. and Shekar, M. (For the Maternal and Child Undernutrition Study Group) (2008) Maternal and child under nutrition 3 . What works interventions for maternal and child under nutrition and survival. The Lancet Series.

[3] The Lancet (2008) Executive summary. The Lancet Nutrition Series. http://www.globalnutritionseries.org/series

[4] WHO (2011) Evidence of Essential nutrition action draft. Geneva.

http://www.who.int/nutrition/EB128_18_backgroundpape $\underline{\text { r2 A reviewofhealthinterventionswithaneffectonnutrition }}$ .pdf

[5] Guyon, A.B. and Quinn, V.J. (2011) Essential nutrition action frame work. Training guide for health workers. Core Group, Washington DC.

[6] Sanghvi, T., Diene, S., Murray, J. and Galloway, R. (1999) Program review of nutrition interventions: Checklist for district health services. The Basic Support for Institutionalizing Child Survival (BASICS) Project, Arlington.

[7] Bryce, J., el Arifeen, S., Pariyo, G., Lanata, C., Gwatkin, D., Habicht, J.P. and the Multi-Country Evaluation of IMCI Study Group (2003) Reducing child mortality: Can public health deliver? Lancet, 362, 159-164. http://dx.doi.org/10.1016/S0140-6736(03)13870-6

[8] Ceesay, S.M., Prentice, A.M. and Cole, T.J. (1997) Effects on birth weight and perinatal mortality of maternal dietary supplements in rural Gambia: 5 year randomised controlled trial. BMJ, 315, 786-790.

http://dx.doi.org/10.1136/bmj.315.7111.786

[9] Dewey, K.G. and Brown, K.H. (2003) Update on technical issues concerning complementary feeding of young children in developing countries and implications for intervention programs. Food and Nutrition Bulletin, 24, 528.

[10] Dickson, R., Awasthi, S., Williamson, P., Demellweek, C. and Paul, G. (2000) Effects of treatment for intestinal helminth infection on growth and cognitive performance in children: Systematic review of randomised trials. $B M J$, 320, 1697-1701. http://dx.doi.org/10.1136/bmj.320.7251.1697

[11] LINKAGES (2009) Maternal nutrition during pregnancy and lactation. Academy for Educational Development, Washington DC.

[12] Jennings, J. and Beyero, M. (2008) Review of incorporation of essential nutrition actions into public health programs in Ethiopia. Food and Nutrition Technical Assistance (FANTA) Project, NW Washington DC. 